\title{
Catecholaminergic Horizontal and Amacrine Cells in the Ferret Retina
}

\author{
Kent T. Keyser, Harvey J. Karten, Barrett Katz, ${ }^{1}$ and Martha C. Bohn ${ }^{2}$ \\ Department of Neurosciences and 'Department of Ophthalmology, University of California San Diego, La Jolla, California \\ 92093, and 2Department of Neurobiology and Behavior, State University of New York at Stony Brook, Stony Brook, New \\ York 11794
}

Enzymes involved in the synthesis of catecholamines were detected in amacrine and what appeared to be a specific class of horizontal cells in the ferret retina. Antisera directed against the enzymes tyrosine hydroxylase (TH), which converts tyrosine to DOPA, and phenylethanolamine $\boldsymbol{N}$-methyltransferase (PNMT), which converts norepinephrine to epinephrine, were used with conventional immunohistochemical techniques. A population of perikarya located at the outer margin of the inner nuclear layer (INL) exhibited TH-like immunoreactivity. The cell bodies were 9-12 $\mu \mathrm{m}$ in diameter and gave rise to stout dendrites that tapered rapidly after emergence from the somata. The processes formed a planar array in the inner half of the outer plexiform layer (OPL) slightly external to the cells of origin. We could not detect any inwardly directed processes. A population of PNMTpositive cells was also observed in the outer tier of cells in the INL. These cells were very similar to those exhibiting TH immunoreactivity. An apparent difference between the 2 populations was that there were areas of intense, somewhat punctate PNMT immunoreactivity in the outer OPL. These were not observed in the TH-stained sections.

Examination of horizontal sections showed that each THpositive cell body gave rise to 4-5 major dendrites that branched to form a roughly circular dendritic field. In the periphery of the retina, an individual cell's dendrites encompassed an area up to $170 \mu \mathrm{m}$ in diameter. The dendritic fields of cells near the center of the retina were substantially smaller. The PNMT-positive cells in horizontal sections appeared identical with respect to cell size and dendritic field characteristics. In the central retina, there were about 200 cells/ $\mathbf{m m}^{2}$ with substantial overlap of dendrites of neighboring cells. On the bases of somatic position, dendritic field size and pattern, and the apparent lack of an axon terminal, we suggest that these cells correspond to the A-type horizontal cells described in cat (Kolb, 1974; Boycott et al., 1978).

As in other vertebrates, a prominent population of THpositive amacrine cells was observed in the inner tiers of the INL. These cells arborized in the inner, middle, and outer laminae of the inner plexiform layer (IPL). The TH-positive

\footnotetext{
Received Dec. 29, 1986; revised May 26, 1987; accepted May 29, 1987.

We thank Christine Laverack, Margaret Leong, Carol Huber, and Janet Mensik for their excellent technical assistance. We also thank Susan K. McConnell and Simon LeVay of the Salk Institute for Biological Studies for their generous cooperation in this project. Supported by PHS Grant EY 06890 to H.J.K.

Correspondence should be addressed to Kent T. Keyser, Department of Neurosciences, M-008, University of California San Diego, Ia Jolla, CA 92093.

Copyright (C) 1987 Society for Neuroscience $0270-6474 / 87 / 123996-09 \$ 02.00 / 0$
}

amacrine cells were clearly distinguishable from the immunoreactive cells in the outer tier of the INL by their position, branching pattern, and intensity of staining.

The identification of neurotransmitters in the vertebrate retina remains central to attempts to understand retinal function. A large number of transmitter candidates have been reported in amacrine cells including $\mathrm{ACh}$, as demonstrated by choline acetyl transferase localization (Millar et al., 1987), indolamines (Floren and Hansson, 1980), and a number of neuropeptides such as substance P (Karten and Brecha, 1980), enkephalin (Brecha et al., 1979), neurotensin (Brecha and Karten, 1980), somatostatin (Brecha and Karten, 1980), and glucagon (Kuwayama et al., 1982). Catecholamines, in particular, have been studied extensively with both formaldehyde histofluorescence methods (Ehinger, 1982) and immunohistochemistry. The immunohistochemical studies have usually relied upon antisera directed against enzymes involved in synthesis of catecholamines. One of these enzymes is tyrosine hydroxylase (TH), which converts tyrosine to 3,4-dihydroxyphenylalanine (DOPA). This reaction is the ratc-limiting step in the pathway. A number of investigators have shown that the distribution of this compound in amacrine cells is similar in many different species (Brecha, 1983; Witkovsky et al., 1984; Park et al., 1986). Specifically, THpositive cell bodies are found at the inner border of the inner nuclear layer (INL) and distinct dendritic arborizations are present in the outermost lamina of the inner plexiform layer (IPL) and, in some species, middle and/or inner laminae as well. The presence of TH in these cells has been interpreted to mean that they are dopaminergic. Less frequently, a population of presumed dopaminergic interplexiform cells has been described as well (Ehinger et al., 1969; Dowling and Ehinger, 1978).

Another catecholamine-synthesizing enzyme, phenylethanolamine $N$-methyltransferase (PNMT), converts norepinephrine into epinephrine. The immunohistochemical detection of this enzyme within other neurons in the INL has been interpreted to mean that some amacrine cells are adrenergic (Hadjiconstantinou et al., 1984).

Less information is available regarding the identity of the transmitters used by bipolar, horizontal and ganglion cells. An exception to this is the considerable evidence that $H 1$ horizontal cells of some non-mammalian vertebrates contain GABA (Marc et al., 1978; Hollyfield et al., 1979; Lam et al., 1979; Schwartz, 1982).

The identity of the transmitter(s) used by mammalian horizontal cells remains unclear. Previous studies of these cells have dealt primarily with morphology and connections. It is known 


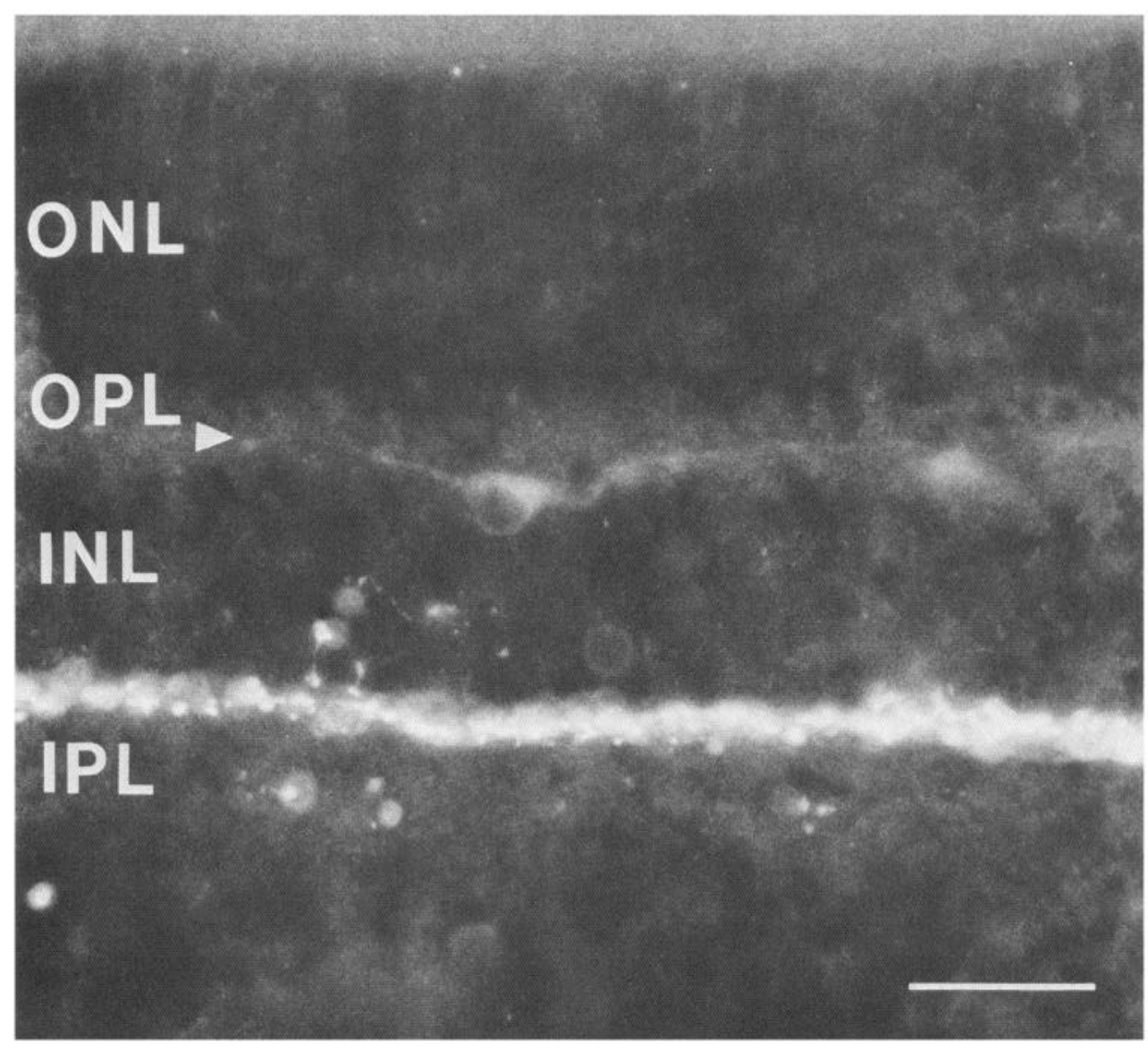

Figure 1. Fluorescence micrograph of a cross section of a ferret retina processed for TH immunoreactivity using the indirect immunofluorescence technique. An immunoreactive cell body is present in the outer INL and its processes project into the OPL. The bands of intense immunoreactivity at the INLIPL border are processes of positive amacrine cells. The major divisions of the retina are indicated. Inner nuclear layer $(I N L)$, outer nuclear layer $(O N L)$, inner plexiform layer $(I P L)$, and outer plexiform layer $(O P L)$. Calibration bar, $25 \mu \mathrm{m}$. that there are 2 morphologically distinct types of horizontal cells in the cat (Kolb, 1974; Boycott et al., 1978). The A-type has a large dendritic field and reportedly lacks an axon or axon terminal. The dendrites give rise to fine processes that end in aggregrates of terminals. These constitute the majority of conventional (i.e., nonphotoreceptor) presynaptic processes in the outer plexiform layer (OPL) (Fischer and Boycott, 1974). The dendrites of the B-type branch more extensively, overlap each other more frequently and form a smaller field than the A-type. In contrast to the A-type, the B-type has an axon and axon terminal.

Recently, Schnitzer and Rusoff (1984) reported the transient appearance of glutamic acid decarboxylase (GAD) in horizontal cells during early development of the rat retina. Similarly, Nishimura et al. (1986) reported the presence of GAD in horizontal cells of a primate retina. Neither of these studies specified what fraction of the total population was GAD positive nor did they indicate if the immunoreactive cells fitted into one of the 2 categories described above.

The present study reports the detection of catecholaminesynthesizing enzymes in amacrine cells and, more importantly, in a population of horizontal cells of the ferret retina. These cells appear to correspond to the A-type horizontal cells of cat and monkey. Our findings are significant in that they suggest a morphological substrate for catecholaminergic effects on information processing in the OPL.

\section{Materials and Methods}

Tissue preparation. Male and female ferrets (Mustela putorius furo) were used in this study. The animals were killed by an overdose of ketamine and xylazine and then perfused via the left ventricle and aorta with 100

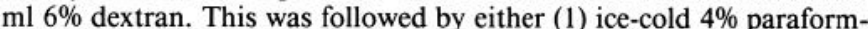
aldehyde in $0.1 \mathrm{M}$ phosphate buffer solution (PBS) at pH 7.4 or (2) 500

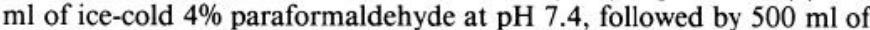
cold $4 \%$ paraformaldehyde and $0.05 \%$ glutaraldehyde and finally another $500 \mathrm{ml}$ of cold $4 \%$ paraformaldehyde. Additional fixative was injected into the posterior chamber of the eye. Each eye was incised at the corneoscleral junction, the vitreous was removed as completely as possible, and the eye placed in fixative for $2-12 \mathrm{hr}$, then transferred to 0.1 M PBS with $20-30 \%$ sucrose to minimize damage resulting from freezing.

The eyecup was immersed in high-viscosity embedding medium (OCT), frozen with dry ice, mounted on a cryostat chuck and sectioned (5-15 $\mu \mathrm{m})$ perpendicularly to the vitreal surface. Sections were collected on gelatin-coated slides and stored at approximately $-20^{\circ} \mathrm{C}$. Alternatively, radial cuts were made from the periphery towards the center of the retina, allowing it to be flattened or divided into several flat pieces. These were placed on a level, frozen cryoform platform on the stage of a sliding microtome, frozen and sectioned $(30-40 \mu \mathrm{m})$ parallel to the vitreal surface. Tissue treated in this fashion was processed "free-floating" in small vials. The solutions, times, and temperatures were identical to those for material on slides, except where otherwise noted.

Staining procedures. The indirect immunofluorescence and avidinbiotin techniques were used in this study. Cryostat-sectioned material on slides was first washed in $0.1 \mathrm{~m}$ sodium phosphate buffer at $\mathrm{pH} 7.4$ and then drained. A rabbit antibody directed against bovine TH (Eugenetech) diluted $1: 500$ or $1: 1000$ in $0.3 \%$ Triton X-100 was applied and the tissue incubated at $4^{\circ} \mathrm{C}$ for $24-48 \mathrm{hr}$. Alternatively, a rabbit antibody directed against rat PNMT (Bohn et al., 1987) diluted 1:1000 or 1:4000 was used. The tissue was then washed in 2 changes of phosphate buffer at $\mathrm{pH}$ 7.4. For immunofluorescence studies, a fluorescein isothiocyanate-coupled goat anti-rabbit antibody diluted $1: 100$ in $0.3 \%$ Triton X-100 was applied and, in the case of tissue already on slides, kept in a humid chamber for $1 \mathrm{hr}$ at room temperature. They were washed again in buffer and coverslipped using a glycerine-carbonate buffer. Alternatively, following incubation in primary antiserum and 


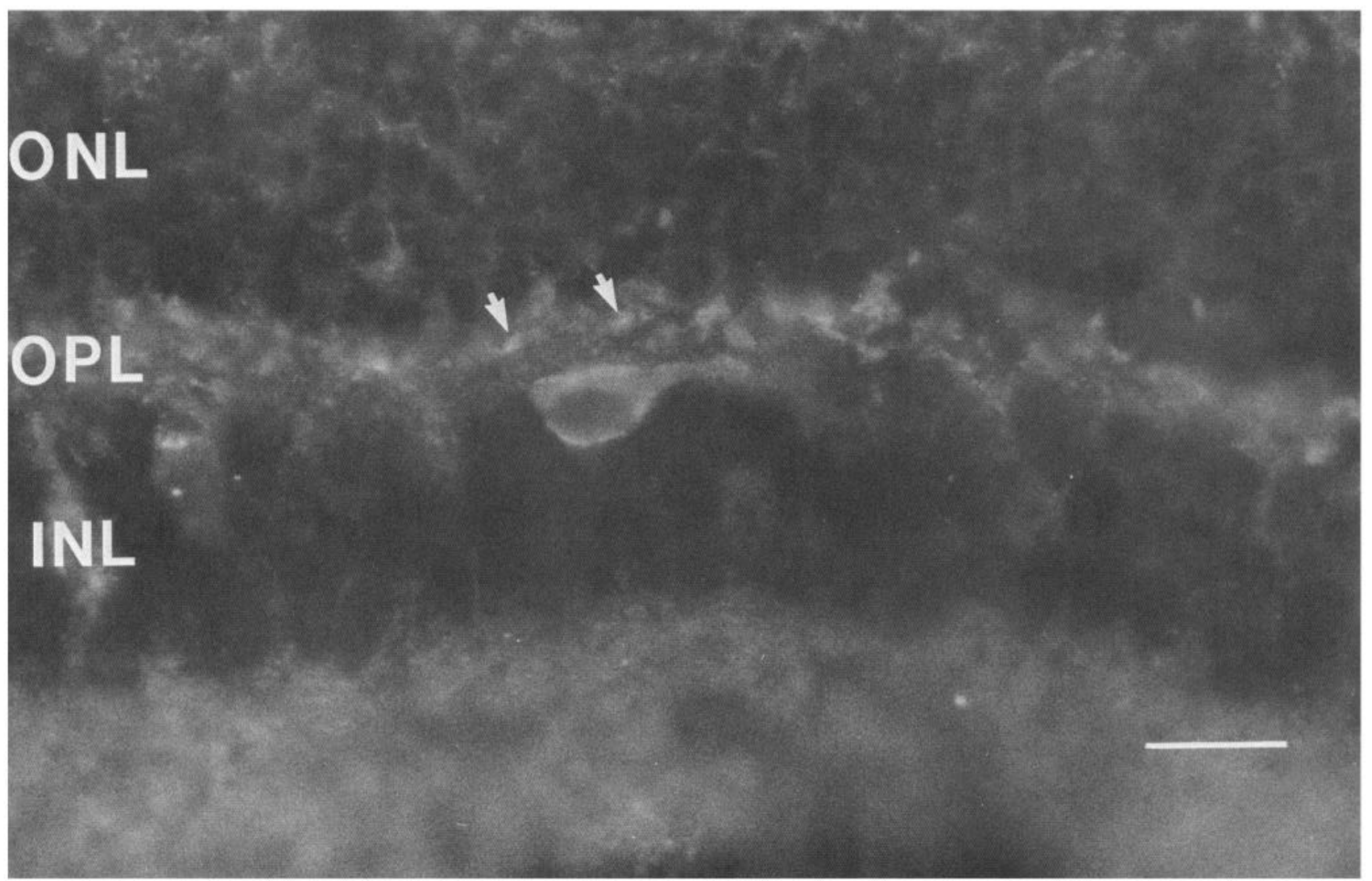

Figure 2. Fluorescence micrograph of a cross section of a ferret retina showing PNMT-like immunoreactivity. A stained cell body can be seen in the outer INL and a portion of a dendrite from this cell extends laterally. Note the punctate immunoreactivity in the outer OPL (arrows). Calibration bar, $15 \mu \mathrm{m}$.

washing, the sections were incubated in biotinylated goat anti-rabbit antibody diluted $1: 200$ in $0.3 \%$ Triton $\mathrm{X}-100$ for $1 \mathrm{hr}$ at room temperature. The tissue was then washed in 2 changes of phosphate buffer for $30 \mathrm{~min}$, drained, and incubated in avidin-coupled peroxidase diluted 1:100 in Triton X-100 for $1 \mathrm{hr}$. After washes in buffer, the sections were incubated with $0.05 \%$ diaminobenzidine in phosphate buffer for $15 \mathrm{~min}$. Hydrogen peroxide was added to make a final concentration of $0.01 \%$, and gentle shaking was applied as the reaction proceeded. After about $15 \mathrm{~min}$, the solution was poured off and the tissue washed in several changes of buffer. Sections were mounted on gelatin-coated slides, cleared, and coverslipped. In some instances, the primary antibody incubation was omitted and staining was abolished.

Selected sections processed for immunofluorescence were photographed with a microscope equipped for fluorescence using high-speed film. Tissues processed with the avidin-biotin technique were photographed with differential interference contrast optics.

\section{Results}

The ferret retina is approximately $200 \mu \mathrm{m}$ thick in the region near the optic nerve head. The IPL is about $40-45 \mu \mathrm{m}$, the INL is $40 \mu \mathrm{m}$ thick, and the OPL about $10 \mu \mathrm{m}$. Two populations of $\mathrm{TH}$-immunoreactive neurons were observed in the INL. One type was found in the outer tier of cells in the INL and had cell bodies $9-13 \mu \mathrm{m}$ in diameter (Fig. 1). Their dendrites could be followed laterally and slightly externally into the OPL toward other immunoreactive cells. The TH immunoreactivity was not observed in the outermost OPL in the area where fine branches and terminals would be expected. Based upon the position, size, and branching pattern of these cells, we tentatively identified them as horizontal cells.
A population of cells exhibiting PNMT immunoreactivity was also observed in the outer INL (Fig. 2). The size of the cell bodies was in the same range as the $\mathrm{TH}$-immunoreactive cells. Dendrites from these cells projected laterally and slightly externally into the OPL, as did the dendrites from the TH-positive cells. In the outer OPL, the PNMT immunoreactivity appeared somewhat punctate and generally more pronounced than the $\mathrm{TH}$ reactivity (Fig. 2, arrows). These features may correspond to the fine branches and terminal aggregates of A-type horizontal cells of the cat as described by Kolb (1974). We never observed processes from the TH- or PNMT-reactive cells in the outer tier of the INL projecting toward the inner INL or IPL.

We also observed TH-positive amacrine cells in the innermost tier (Fig. 3) of the INL. They arborized primarily in the outer layer of the IPL. Some processes traversed the IPL and formed sparse arborizations in the middle and inner strata of the IPL (Fig. 4). These laminae seemed to correspond to laminae 1, 3, and 5 as defined in other vertebrates (see Ehinger, 1982). The outermost arborization was always considerably broader and more intensely stained than the other two. This pattern is very similar to that reported for TH-positive amacrine cells in other vertebrates (see Brecha, 1983). We also observed small-caliber, sometimes beaded TH-reactive processes traversing the INL between the IPL and the OPL. In some cases these processes appeared to originate from the inner INL or outer IPL, but we were unable to determine the cells of origin. Similar processes were not observed in the PNMT-stained sections. We suggest that these fibers are equivalent to the catecholaminergic inter- 


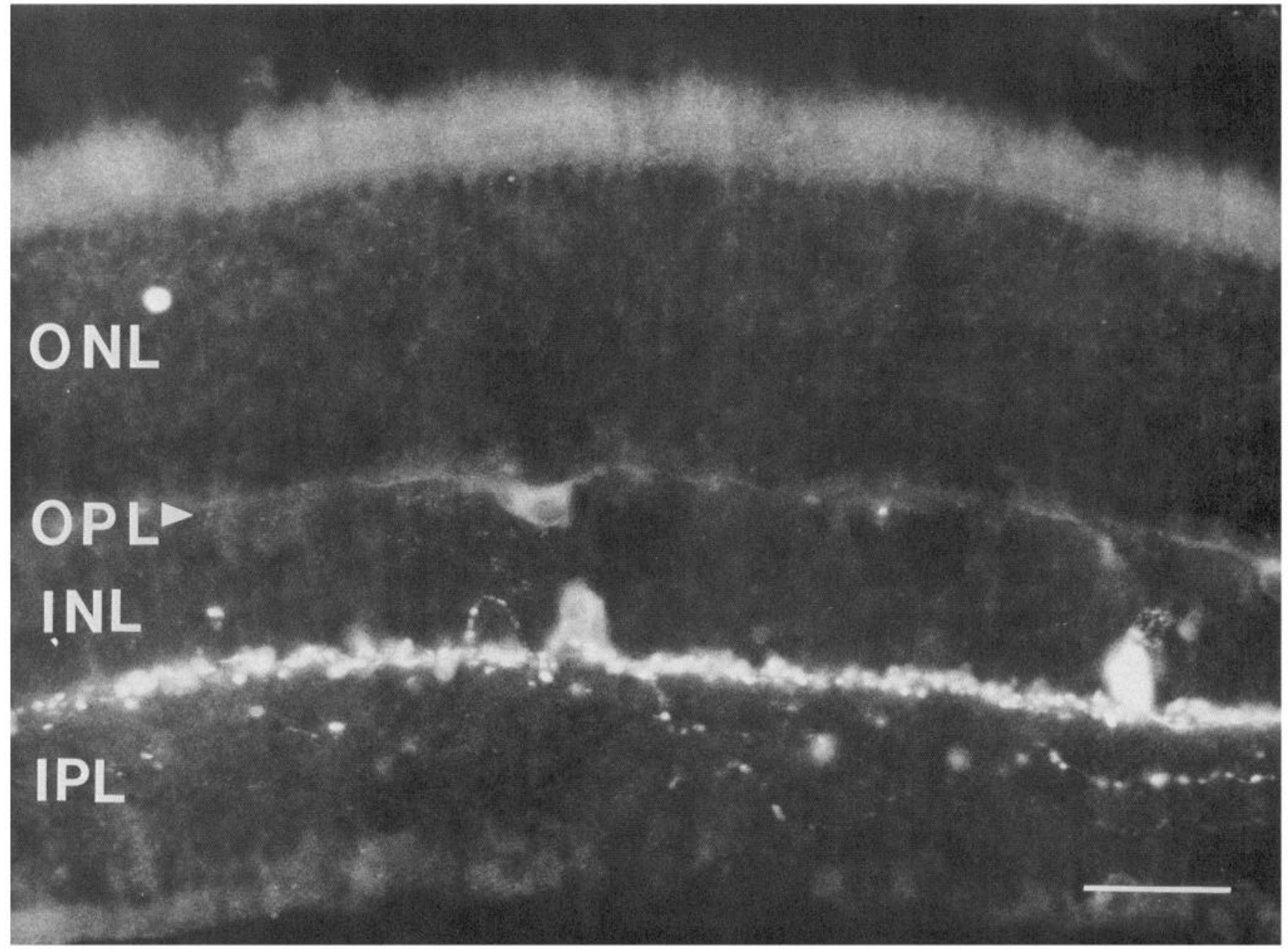

Figure 3. Cross section of ferret retina showing TH-positive horizontal and amacrine cells. The amacrine cell processes arborize in 3 discrete laminae of the IPL, while the horizontal cell processes are confined to the OPL. Calibration bar, $30 \mu \mathrm{m}$.

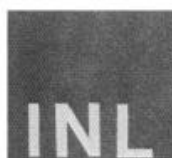

Figure 4. Fluorescence micrograph of amacrine cell processes in the IPL. This tissue was treated for TH immunofluorescence. The stained processes are very dense in the outer IPL but much sparser in the middle and inner laminae. Calibration bar, $30 \mu \mathrm{m}$. 


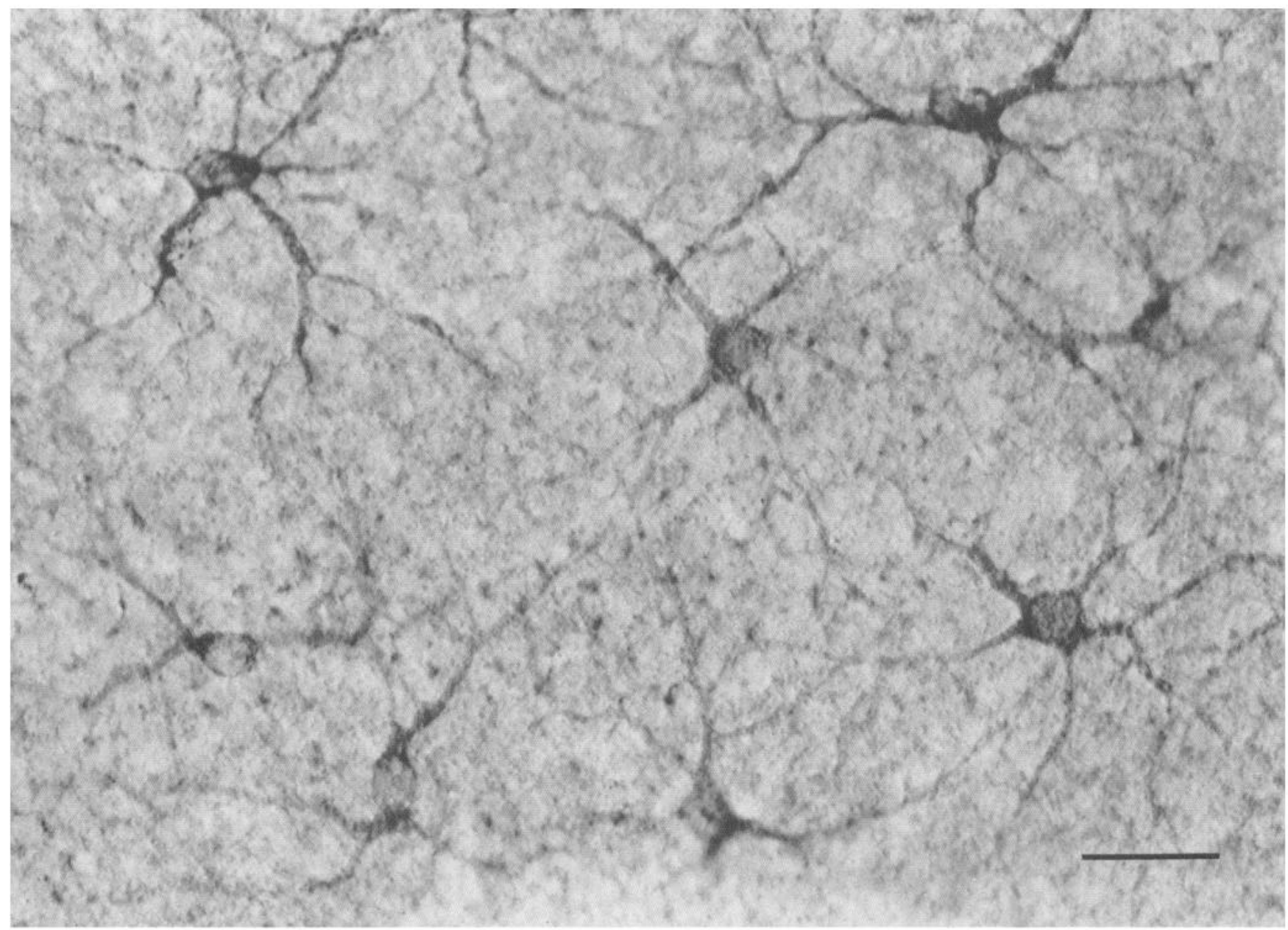

Figure 5. Light micrograph of a horizontal section of the ferret retina. This tissue was processed using anti-TH antibody and the avidin-biotin peroxidase technique. The primary dendrites of the cells are in the same plane of focus as the cell bodies. Note the extensive overlap of the dendrites of neighboring cells. Calibration bar, $20 \mu \mathrm{m}$.

plexiform processes as described for other vertebrates (Dowling and Ehinger, 1978).

The size of an individual cell's dendritic field and estimates of the density of cells in the retina were determined in material sectioned parallel to the vitreal surface and then processed as described above. The horizontal cells exhibiting TH-like immunoreactivity were distinguishable from the TH-positive amacrine cells by the position of their cell bodies within the retina, their distinctive branching pattern and by a difference in the intensity of staining (compare Fig. 5 to Fig. 7 below). In the central retina, the TH-positive horizontal cells numbered about 200 cells $/ \mathrm{mm}^{2}$, decreasing to about $80-100$ cells $/ \mathrm{mm}^{2}$ in the periphery. There was a significant degree of overlap of dendrites from adjacent TH-positive horizontal cells (Fig. 5). Each THimmunoreactive horizontal cell body gave rise to 4 or 5 usually nonoverlapping primary dendrites which formed a more or less circular dendritic field (Fig. 6). The major dendrites of a single cell in the peripheral areas of the retina encompassed an area as large as $170 \mu \mathrm{m}$ in diameter. This figure decreased towards the center of the retina, but the greatly increased cell density prevented precise measurements. We were unable to identify horizontal cell axons or axon terminals. These cells appear to correspond to the A-type horizontal cells as described by Kolb (1974) and Boycott et al. (1978).
The PNMT-positive cells, as viewed in horizontal sections, were very similar to the TH-positive horizontal cells (Fig. 7). Each PNMT-reactive cell body also gave rise to 4-5 nonoverlapping dendrites, which, in the central retina, formed a roughly circular dendritic field. As with the TH-positive cells, we were unable to detect axons or axon terminals in the PNMT-stained sections. The density of the PNMT cells was about the same as that of the TH-positive cells. In some horizontal sections processed for PNMT staining, very small clusters of heavily stained structures were observed in the outer OPL. We suspect that these represent terminal aggregates as described by Kolb (1974) and Fisher and Boycott (1974). These were not found in the tissue processed with the TH antibody.

Each TH-positive amacrine cell body gave rise to 3-4 major dendrites, which repeatedly branched and, in contrast to the horizontal cells, formed an extremely dense meshwork in lamina 1 (Fig. 8). We were unable to determine the area encompassed by a single cell's dendritic field due to the density of stained processes in lamina 1 .

\section{Discussion}

Amacrine cells

The TH-positive amacrine cell population in the ferret retina is similar to that reported for other vertebrates. The immuno- 


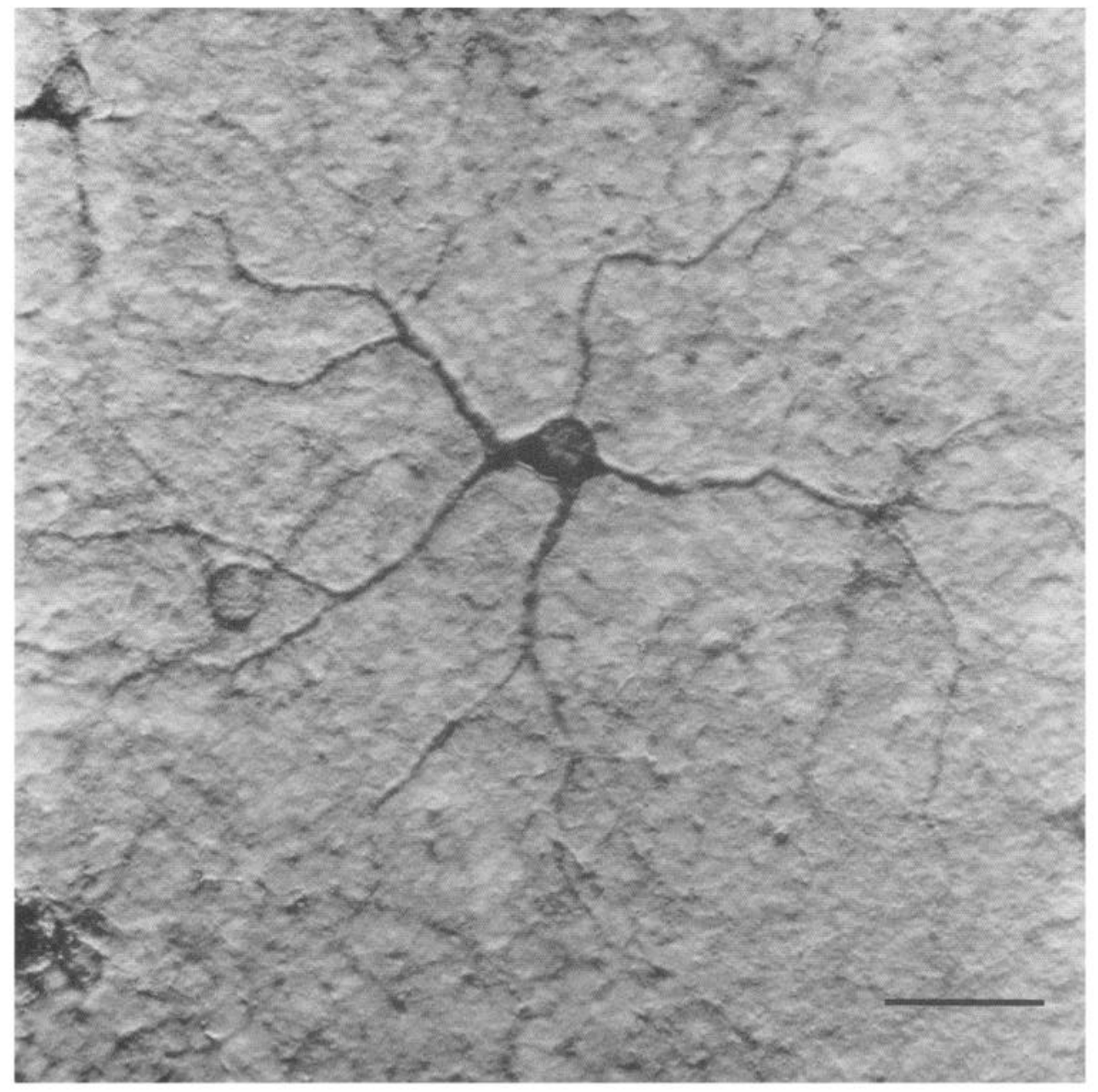

Figure 6. Light micrograph of a horizontal section of ferret retina processed for TH as in Figure 5. Note the planar, nonoverlapping dendrites and the large area covered. Calibration bar, $25 \mu \mathrm{m}$. reactive perikarya were found in the inner tier of the INL, adjacent to the outer margin of the IPL, as has been reported for other species (Ehinger, 1982; Brecha, 1983). The same trilaminar pattern of reactive processes observed in ferret has been previously reported for turtles, birds, and other mammals (Dowling and Ehinger, 1978; Floren, 1979; Witkovsky et al., 1984). An apparent exception seems to be the Sprague-Dawley rat, which has TH-positive cells in the lowest tier of the INL and fibers only in the outermost IPL (Park et al., 1986). The same study also reported the presence of a population of cells in the inner portion of the INL, which exhibited PNMT immunoreactivity but not $\mathrm{TH}$, aromatic L-amino acid decarboxylase (AADC) or dopamine $\beta$-hydroxylase (DBH) reactivity. A much smaller population of PNMT-positive neurons in the INL exhibited TH, PNMT, and AADC, but not DBH, immunoreactivity. An earlier study by Hadjiconstantinou et al. (1984) reported a class of PNMT-positive cells in the second tier of cells in the INL, a sparse population of fibers in the outer IPL and a much more dense plexus in the middle of the INL. This study concluded that the TH-positive amacrine cells and the PNMT cells were distinctly different cell populations.

In addition, the question of catecholaminergic interplexiform cells in the rat retina seems unresolved. One study (Foster et al., 1985) reported the existence of TH-positive varicose fibers in the OPL of the rat. These fibers were not visible in tissue stained for PNMT or DBH. However, the more recent report of Park and his collaborators (1986) made no mention of the localization of any catecholamine biosynthetic enzyme in the OPL.

These studies indicate an extremely complex system of catecholamine neurons in the mammalian retina. Whether the data from other, less intensively studied mammalian retinae will mirror the situation in rat is unclear.

\section{Horizontal cells}

On the grounds of location within the retina, branching pattern, dendritic field size, and the absence of identifiable axons and axon terminals, we have tentatively identified the TH- and PNMT-positive cells in the outer INL as A-type horizontal cells. These results suggest that horizontal cells may be catecholaminergic.

A recent study (Sandell and Lam, 1986) reported the existence of an indoleamine-accumulating neuron in the rabbit retina, designated as a Type 3 neuron. These cells share many characteristics with the TH/PNMT-positive horizontal cells described above. In view of the fact that both catecholaminergic and indolaminergic neurons can take up the same precursors (Iversen, 1975), we reexamined our preparations with the morphology of the Type 3 cell in mind. The Type 3 cell has a cell body in the outer INL and extends processes into both the OPL and the IPL. We did not find any inwardly directed processes projecting from the TH/PNMT-reactive cells in the ferret. The 


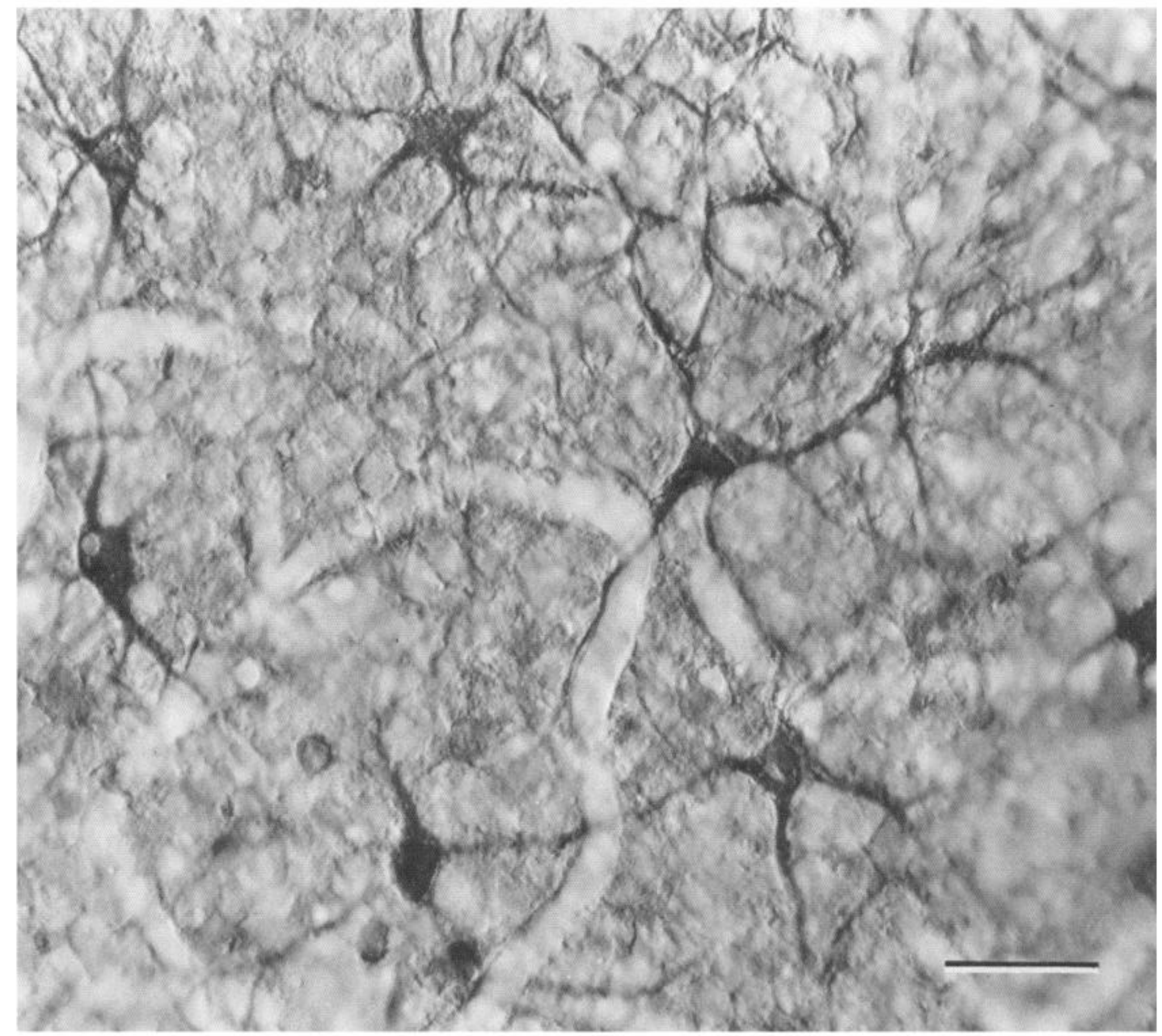

Figure 7. Light micrograph of a horizontal section of the ferret retina stained for phenylethanolamine $N$-methyltransferase (PNMT). Note the planar dendritic fields and the general similarity to the cells shown in Figure 5. Calibration bar, $25 \mu \mathrm{m}$.

TH-positive processes, which we thought to be interplexiform fibers, might originate from the horizontal cells, although we were unable to confirm this suggestion. However, this seems unlikely, as these fibers were never seen in the PNMT-stained material. Additionally, the fibers that we interpreted as interplexiform processes were sometimes beaded, of small caliber, and frequently coursed laterally in the INL as it projected outward. In contrast, the Type 3 cell apparently has a short inwardly directed process and does not appear to extend laterally as it traverses the INL. Finally, the Type 3 cells have much lower densities than the cells in the present report. The Type 3 cell has its highest density of 6 cells $/ \mathrm{mm}^{2}$ in the ventral retina, while the putative Type A TH/PNMT-positive horizontal cell has its peak density of about 200 cells $/ \mathrm{mm}^{2}$ in the central retina. In spite of these differences, however, we cannot yet conclude that the 2 populations are distinct.

The question of co-occurrence of PNMT and TH immunoreactivity in ferret horizontal cells cannot be resolved from our data. The fact that both the primary antisera available to us were generated in rabbits precluded reliable double-label studies. If both enzymes do, in fact, occur in the same cells, it would indicate that the A-type horizontal cells in the ferret may use epinephrine as a neurotransmitter. It is also possible that there are 2 A-type subtypes that both produce enzymes involved in the synthesis of catecholamines. In the cat, there are reported to be 75,000 A-type horizontal cells with the density at the periphery of the retina about $110-130$ cells $/ \mathrm{mm}^{2}$ increasing to over $700 \mathrm{cells} / \mathrm{mm}^{2}$ in the central area (Wässle et al., 1978). Although we are not aware of any quantitative information concerning retinal cell types in mustelids, there is no reason to assume that the density and total number of A-type cells in ferret is substantially higher than that in cat. It seems reasonable to conclude, then, that the cells that exhibit TH and/or PNMT immunoreactivity comprise a significant fraction of the total A-type horizontal cell population.

Despite a number of studies of the vertebrate retina using techniques such as formaldehyde histofluorescence and immunohistochemistry, there are, to our knowledge, no prior reports of the detection of catecholamines or their synthesizing enzymes in any vertebrate horizontal cells. We can only speculate as to the reasons for this. It is possible that TH and its synthesizing enzymes are present in horizontal cells of other vertebrates but in amounts below the detection sensitivity of current techniques or in a nonreactive form. An alternative explanation is that the transmitter content of ferret retinal neurons is different from that in other vertebrates. Since the pattern of TH immunoreactivity in ferret amacrine cells is similar to that reported for other vertebrates, this seems unlikely. Neither 


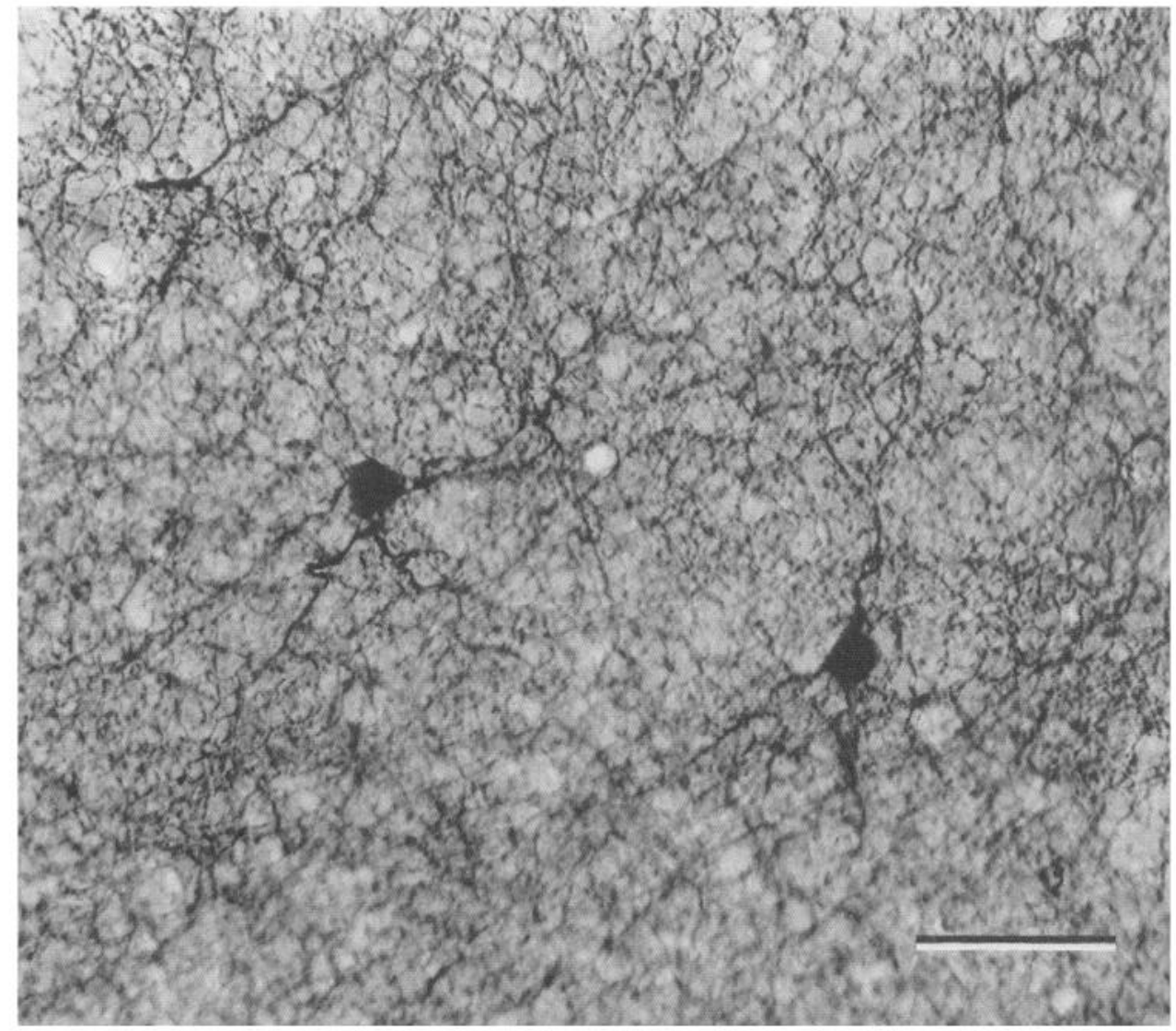

Figure 8. Light micrograph of a horizontal section of the ferret retina at the INL-IPL border. The tissue was processed for TH immunoreactivity. Note the stained cell bodies and the extremely dense arborization in the outer IPL. Calibration bar, $50 \mu \mathrm{m}$. can we ignore the possibility that the antisera used in this study reacted with some intracellular constituent other than $\mathrm{TH}$, although our previous experience with the antibody suggests this is not the case.

Similar arguments apply for the results from the PNMT studies. However, the antiserum we used is directed against rat PNMT. Previous studies have employed PNMT antisera directed against bovine or rabbit enzyme.

The unavailability of data concerning the physiology or biochemistry of mammalian horizontal cells precludes conclusions about the possible functional significance of our observations. Ultrastructure studies of cat retina have indicated that the dendritic terminals of both A- and B-type horizontal cells constitute some of the lateral elements of cone triads. The central element is contributed by the cone bipolar cell. This arrangement suggests that there may be direct adrenergic influence on information transfer in the OPL.

\section{References}

Bohn, M. C., C. F. Dreyfus, W. J. Friedman, and K. A. Markie (1987) Glucocorticoid effects on phenylethanolamine N-methyltransferase (PNMT) in explants of embryonic rat medulla oblongata. Dev. Brain Res. (in press).

Boycott, B. B., L. Peichl, and H. Wässle (1978) Morphological types of horizontal cell in the retina of the domestic cat. Proc. R. Soc. London [Biol.] 203: 229-245.

Brecha, N. (1983) Retinal neurotransmitters: Histochemical and biochemical studies. In Chemical Neuroanatomy, P. E. Emson, ed., pp. 85-130, Raven, New York.

Brecha, N., and H. J. Karten (1980) Localization of enkephalin, substance $\mathrm{P}$, neurotensin and somatostatin immunoreactivity within amacrine cells of the retina. Anat. Rec. 196: 225.
Brecha, N., H. J. Karten, and C. Laverack (1979) Enkephalin-containing amacrine cells in the avian retina: Immunohistochemical localization. Proc. Natl. Acad. Sci. USA 76: 3010-3014.

Dowling, J., and B. Ehinger (1978) Synaptic organization of the dopaminergic neurons in the rabbit retina. J. Comp. Neurol. 180: 203220.

Ehinger, B. (1982) Neurotransmitter systems in the retina. Retina 2: 305-321.

Ehinger, B., B. Falck, and A. M. Laties (1969) Adrenergic neurons in teleost retina. Z. Zellforsch. 97: 285-297.

Fisher, S. K., and B. B. Boycott (1974) Synaptic connexions made by horizontal cells within the outer plexiform layer of the retina of the cat and the rabbit. Proc. R. Soc. London [Biol.] 186: 317-331.

Floren, I. (1979) Indoleamine accumulating neurons of the pigeon and chick: A comparison with dopaminergic neurons. Acta. Ophthalmol. 57: $198-210$.

Floren, I., and H. C. Hansson (1980) Investigations into whether 5 -hydroxytryptamine is a neurotransmitter in the retina of rabbit and chicken. Invest. Ophthalmol. Vis. Sci. 19: 117-125.

Foster, G. A., T. Hökfelt, J. T. Coyle, and M. Goldstein (1985) Immunohistochemical evidence for phenylethanolamine- $N$-methyltransferase-positive/tyrosine hydroxylase-negative neurones in the retina and the posterior hypothalamus of the rat. Brain Res. 330:183188.

Hadjiconstantinou, M., A. P. Mariani, P. Panula, T. H. Joh, and N. H. Neff (1984) Immunohistochemical evidence for epinephrine-containing retinal amacrine cells. Neuroscience 13: 547-551.

Hollyfield, J. G., M. E. Rayborn, P. V. Sarthy, and D. M. K. Lam (1979) The emergence localization and maturation of neurotransmitter systems during development of the retina of Xenopus laevis. J. Comp. Neurol. 188: 587-598.

Iversen, L. L. (1975) Uptake processes for biogenic amines. In Handbook of Pyschopharmacology, L. L. Iversen, S. D. Iversen, and S. H. Snyder, eds., pp. 381-442, Plenum, New York.

Karten, H. J., and N. Brecha (1980) Localization of substance P immunoreactivity in amacrine cells of the retina. Nature 283: 87-88. 
Kolb, H. (1974) The connections hetween horizontal cells and photoreceptors in the retina of the cat: Electron microscopy of Golgi preparations. J. Comp. Neurol. 155: 1-14.

Kuwayama, Y., I. Ishimoto, M. Fukuda, Y Shimizu, S. Shiosaka, S. Inagaki, E. Senba, M. Sakanaka, H. Takagi, H. Takatsuki, Y. Hara, T. Kawai, and M. Tohyama (1982) Overall distribution of glucagonlike immunoreactivity in the chicken retina: An immunohistochemical study with flat mounts. Invest. Ophthalmol. 22: 681-686.

Lam, D. M. K., Y. Y. T. Su, I. Swain, R. E. Marc, C. Brandon, and J. $\mathrm{K}$. Wu (1979) Immunocytochemical localization of L-glutamic acid decarboxylase in the goldfish retina. Nature 258: 565-567.

Marc, R. E., W. E. Stell, D. Bok, and D. M. K. Lam (1978) GABAergic pathways in the goldfish retinas. J. Comp. Neurol. 182: 221-226.

Millar, T. J., I. Ishimoto, I. W. Chubb, M. L. Epstein, C. D. Johnsona, and I. G. Morgan (1987) Cholinergic amacrine cells of the chicken retina: A light and electronmicroscope study. Neuroscience (in press).

Nishimura, Y., M. L. Schwartz, and P. Rakic (1986) GABA and GAD immunoreactivity of photoreceptor terminals in primate retina. Nature 320: 753-756.
Park, D. H., G. Teitelman, M. J. Evinger, J. I. Woo, D. A. Ruggiero, V. R. Albert, E. E. Baetge, V. M. Pickel, D. J. Reis, and T. H. Joh (1986) Phenylethanolamine $\mathrm{N}$-methyltransferase-containing neurons in the rat retina: Immunohistochemistry, immunochemistry and molecular biology. J. Neurosci. 6: 1108-1113.

Sandell, J. H., and D. M. K. Lam (1986) A system of indolamineaccumulating neurons in the rabbit retina. J. Neurosci. $6: 3331-3347$,

Schnitzer, J., and A. C. Rusoff (1984) Horizontal cells of the mouse retina contain glutamic acid decarboxylase-like immunoreactivity during early developmental stages. J. Neurosci. 4: 2948-2955.

Schwartz, E. A. (1982) Calcium-independent release of GABA from isolated horizontal cells of the toad retina. J. Physiol. (Lond.) 323: 211-227.

Wässle, H., L. Peichl, and B. B. Boycott (1978) Topography of horizontal cells in the retina of the domestic cat. Proc. R. Soc. London [Biol.] 203: 269-291.

Witkovsky, P., W. Eldred, and H. J. Karten (1984) Catecholamineand indolamine-containing neurons in the turtle retina. J. Comp. Neurol. 228: 217-225. 